\title{
POR LOS CAMINOS DE EUROPA EN EL SIGLO XVIII: EL VI CONDE DE FERNÁN NÚÑEZ Y SU GUÍA DE VIAJE PARA EL CARDENAL RANNUZZI
}

\author{
By the roads of Europe in the eighteenth century: \\ The VI Count of Fernán Núñez and bis travel guide \\ for the Cardinal Rannuzzi
}

\author{
Francisco José ROSAL NADALES \\ IES «Hernán Pérez del Pulgar» (Ciudad Real) \\ fj.rosal68@gmail.com
}

Fecha de recepción: 1/07/2017

Fecha de aceptación definitiva: 21/02/2018

RESUMEN: Entre 1746 y 1795, el VI conde de Fernán Núñez recorrió España y otros países europeos, en unos casos por obligación, en otros para conocer mundo. Sus experiencias las utilizó para optimizar su preparación, mejorar los conocimientos y la forma de vida en su época y, en algunos casos, para ayudar a sus amigos. En 1786 escribió una Ruta de viajes para el nuncio del papa, quien debía trasladarse desde Lisboa a Italia. En ella describió los caminos, las ciudades y los monumentos que podía visitar. También incluyó un mapa manuscrito con las rutas y las ciudades que debía atravesar. Esta guía y el mapa, pues, deben considerarse documentos valiosos para el estudio de los viajes en el siglo XVIII. Su valor aumenta por el hecho de tratarse de una obra de carácter personal y basada en la experiencia propia de un gran viajero.

Palabras clave: VI conde de Fernán Núñez; guía de viaje; siglo XVIII; Portugal; España; Francia.

ABSTRACT: Between 1746 and 1795, the VI Count of Fernán Núñez toured Spain and other European countries, in some cases by obligation, in others to 
know the world. He used his experiences to optimize his preparation, to improve the knowledge and the way of life of his time and, even, to help his friends. Since the papal nuncio had to more fron Lisbon to Italy, in 1786, he wrote a Travel route in which he described the roads, cities and monuments he could visited. He also included a handwritten map with the routes and cities to be crossed. This guide and map are indispensable documents towards the study of travel in the eighteenth century. Its value increases due to the fact that it is a work of a personal nature and it is based on the experience of a great traveller.

Key words: VI Count of Fernán Núñez; travel route; eighteenth century; Portugal; Spain; France.

\section{INTRODUCCIÓN}

Los viajes en el siglo XVIII fueron empresas complicadas. En el caso particular de los desplazamientos por tierra, las dificultades se debieron a que la mayoría de los caminos no eran transitables ni seguros; a la insuficiencia de medios de transporte y su incomodidad, o a la falta de posadas y mesones que hiciesen más llevadero el rigor del desplazamiento. Sin embargo, se viajó, y mucho. En unas ocasiones, por gusto, como en los grandes viajes europeos (de aprendizaje y diversión) que hacían los jóvenes de la aristocracia y que recibieron el nombre de Grand Tour. En otras ocasiones, las más, por necesidad, con el objetivo de ocupar un cargo público, visitar a parientes o incorporarse a una fuerza militar, por citar solo tres ejemplos. En cualquier caso, los traslados en ese tiempo resultaban toda una aventura, no siempre placentera o resuelta con éxito ${ }^{1}$.

De todos estos tipos de viajes disfrutó -y padeció, debe reconocerse- el VI conde de Fernán Núñez, don Carlos José Gutiérrez de los Ríos y Rohan Chabot (Cartagena, 1742-Madrid, 1795), desde su tierna infancia hasta poco antes de su fallecimiento. Además, fue un hombre que aprendía del entorno y vivencias. Educado por los jesuitas en el Seminario de Nobles de Madrid, había adoptado de ellos la necesidad de viajar para mejorar la educación recibida y reconocer el mundo ${ }^{2}$.

Al mismo tiempo, ofrecía a quienes le rodeaban esos conocimientos, aderezados con sus propias máximas sobre la vida. De su experiencia viajera es muestra un diario ${ }^{3}$ donde recogió las características de los caminos, de las residencias

1. Sobre esta cuestión ya investigó y aportó testimonios de la época Rafael Olaechea. Véase Olaechea Albistur, Rafael. «Una viajera rusa del XVIII en los Pirineos Franceses». Anales de la Universidad de Alicante. Historia Moderna, 1982, n. ${ }^{\circ}$ 2, pp. 223-224.

2. Para este asunto, véase Comellas AguirrezÁbal, Mercedes. «Viajes y aprendizaje. Del grand tour dieciochesco al viaje romántico». En NAVARRO DOMínguEz, Eloy (ed.). Imagen del mundo: seis estudios sobre literatura de viajes. Universidad de Huelva, 2014, p. 93.

3. La lectura de este diario manuscrito puede causar problemas, debido a la letra menuda del conde y al carácter de borrador que tiene. Hemos consultado los diferentes manuscritos que pertenecieron al archivo de la Casa Ducal de Fernán Núñez, ahora conservados en la Sección Nobleza del 
donde pernoctó, de las ciudades que visitó, de la agricultura y la economía de las diferentes zonas por las que pasó, etc. Con más claridad en la letra que el anterior diario, se ha conservado una Ruta general de todos mis viajes, documento pasado a limpio donde se anotan, día a día, lo que veía y hacía, las leguas que recorría y dónde estaba en cada uno de esos viajes, con el límite abrupto de 1784, si bien debía recoger sus experiencias viajeras hasta $1793^{4}$.

Mientras Fernán Núñez y otros viajeros españoles buscaban aprender de Europa, tal circunstancia se había vuelto tediosa para algunos jóvenes de las clases adineradas europeas, de manera que se buscaron nuevos destinos en los que instruirse; uno de ellos fue España y, más en concreto, Andalucía, considerada como un lugar lleno de expectativas por su exotismo5.

Los investigadores se han ocupado de este tipo de relatos desde el punto de vista de la literatura y desde la historia. Han tomado como objeto de estudio tanto los escritos por españoles como de quienes llegaron de más allá de nuestras fronteras. Su intención fundamental ha sido «dilucidar hasta qué punto fueron [los viajeros escritores] presa de ideas preconcebidas o bien actuaron como observadores objetivos tanto de las inercias y los atrasos como de los indicios de cambio en la España del siglo XVIII" ${ }^{6}$.

\section{El VI CONDE DE FERNÁN NúÑEZ}

Fue don Carlos José un Grande de España en el sentido literal de la palabra. Perteneció a una familia de la encumbrada nobleza y, aunque su cuna le abrió muchas puertas ${ }^{7}$, supo ascender en méritos hasta la confianza de quienes le trataron, entre ellos el propio rey Carlos III. Gutiérrez de los Ríos fue autor de una biografía del monarca que ha servido como fuente a multitud de historiadores y que, al mismo tiempo, contiene una biografía del aristócrata ${ }^{8}$. Por decisión real se le

Archivo Histórico Nacional (en adelante, AHN-SN) Caja 2033. Sobre el carácter del diario ha trabajado recientemente la profesora Carolina Blutrach. Véase BlutRACH Jelín, Carolina. "Autobiografía y memoria en el Diario de viajes del VI Conde de Fernán Núñez». Espacio, Tiempo y Forma (serie IV, Historia Moderna), 2016, n. ${ }^{\circ}$ 29, pp. 65-84.

4. Esta Ruta hemos podido consultarla en la citada Caja 2033, documento 1.

5. Según se recoge en GARCía-MOnTón, Isabel y García-ROMERAL, Carlos. «Viajeros americanos en Andalucía durante los siglos XIX y XX». Revista Complutense de Historia de América, 2000, n. ${ }^{\circ}$ 26, p. 262.

6. Bolufer Peruga, Mónica. "Civilización, costumbres y política en la literatura de viajes a España en el s. XVIII». Estudis, 2003, n. ${ }^{\circ} 29$, p. 256.

7. Los reyes Fernando VI y Bárbara de Braganza se convirtieron en protectores de don Carlos José y su hermana, doña Escolástica, cuando fallecieron los padres.

8. Véase Conde de Fernán NúÑEz. Vida de Carlos III. Publicada por A. Morel-Fatio y A. Paz y Meliá, con un prólogo de Juan Valera. Madrid: Librería de Fernando Fé, 1898. Existe una versión actual de la Fundación Universitaria Española realizada en Madrid en 1988. De época reciente es la siguiente tesis doctoral: Vigara Zafra, José Antonio. Arte y cultura nobiliaria en la Casa de Fernán Núñez: 
confirieron, entre otros altos cargos, el mando del Regimiento Inmemorial del Rey, el puesto de teniente general de los Reales Ejércitos, la embajada de España en la corte de Lisboa o la representación diplomática en París, esta última en los convulsos tiempos de la Revolución francesa. Recibió las altas distinciones de Caballero del Toisón de Oro, Gran Cruz de la Real Orden de Carlos III o Gentilhombre de Cámara del mismo rey, por citar solo tres ejemplos. Con su decisiva mediación tuvieron lugar las negociaciones y los exitosos festejos para celebrar el doble desposorio entre infantes españoles y portugueses en 1785, con los que se reforzaron las relaciones entre las otrora enemistadas naciones ${ }^{9}$. Él también se encargó de dirigir el rescate de la preciosa carga del navío San Pedro de Alcántara, naufragado en las costas lusas de Peniche a principios de 1786. Mejoró la vida de sus vasallos en la que siempre denominó "su villa» de Fernán Núñez (Córdoba), con la institución de un ramillete de obras caritativas ${ }^{10}$. Incluso fue un artista que encandiló a sus compañeros de armas con su pericia para tañer el violín en los momentos de asueto ${ }^{11}$, asombró a los músicos con un Stabat Mater compuesto casi al final de sus días (Lovaina, 1793) ${ }^{12}$ e ideó una nueva letra para La Marsellesa donde encumbraba a los soldados germanos ${ }^{13}$.

Cuando escribió esta guía para el cardenal Rannuzi, Gutiérrez de los Ríos ocupaba el puesto de embajador de España ante María I de Braganza, Reina Fidelísima de Portugal. Al mismo tiempo y ante la misma corte, el representante

(1700-1850). UNED, 2015, donde se pueden localizar elementos biográficos de don Carlos José Gutiérrez de los Ríos y su relación con las Bellas Artes, así como una imagen y referencias al documento de viaje que es objeto del presente artículo (p. 317). Agradecemos al profesor Vigara el habernos hecho llegar su tesis, pues no se encuentra en acceso abierto.

9. Portugal era tradicional aliada de Inglaterra, mientras que España, en virtud de los Pactos de Familia entre los Borbones de ambos reinos, era aliada de Francia. A lo largo del siglo XVIII, varios enfrentamientos entre las dos potencias arrastraron a sus respectivos socios diplomáticos, los cuales obtuvieron pérdidas o ganancias según la suerte de las armas.

10. Entre otros autores, ha estudiado su labor benéfica José Antonio Vigara. Véase VIGARA Zafra, José Antonio. "Las obras pías del VI Conde de Fernán Núñez: ejemplo de distinción social a través de la caritas ilustrada a finales del siglo XVIII. De Arte, 2015, n. ${ }^{\circ}$ 14, pp. 119-137.

11. Véase el documento inédito AHN-SN, Fernán Núñez, C.1832, D.5 Memorias del Excmo. Sr. Dn. Carlos José Gutiérrez de los Ríos, VI Conde de Fernán Núñez. Las publica acompañadas de un estudio biográfico el Duque de Fernán Núñez, Conde de Cervellón. Madrid, obra inédita, 1934, tomo 1, p. 15 bis [lápiz]. Carta dirigida a la Duquesa del Infantado el día 22 de octubre de 1761.

12. El compositor y musicólogo don Luis Bedmar realizó, en 1993, una edición de la obra a partir del manuscrito que se conservaba en el Monasterio de la Encarnación (Madrid). El Stabat Mater se ha escuchado en nuestros días en Fernán Núñez y Córdoba (1993), así como en Úbeda (2013). Sobre la faceta musical de Gutiérrez de los Ríos, véanse los siguientes artículos: Rosal Nadales, Francisco José. «El VI Conde de Fernán Núñez. Un músico en la corte de Carlos III». Revista de Feria 1999, Ayuntamiento de Fernán Núñez, 1999, pp. 87-88; Rosal Nadales, Francisco José. «El Stabat Mater del Conde de Fernán Núñez (de la mano de don Luis Bedmar y don Leo Brower)». Revista de Feria 2000, Ayuntamiento de Fernán Núñez, 2000, pp. 95-97.

13. Ha sido posible localizar este Hymne des Germains, tel qu'il se chantera par-tout en la AHNSN, Fernán Núñez, C. 2039, D. 2, n. ${ }^{\circ} 25$. 
del papa Giovanni Angelico Braschi, Pío VI, era el citado Rannuzzi. Para él, como símbolo de amistad y altruismo, diseñó don Carlos José la ruta que ahora tratamos. El hecho de que ambos formasen parte de la misión diplomática en Lisboa y el carácter filantrópico de Fernán Núñez, siempre dispuesto a ayudar a quien le necesitase, debieron de influir en su elaboración. El nuncio, no sabemos si por haber terminado su misión o por llamada de Roma, debía trasladarse hasta la Ciudad Eterna, de ahí que emprendiese este largo y penoso viaje armado con los consejos de Fernán Núñez. Sin embargo, la descripción de los caminos termina en Turín, no en Roma. Debe entenderse que este último tramo del viaje era conocido por el nuncio o su séquito, de ahí que no hiciera falta la ayuda del embajador español.

Tanto la guía como el mapa los hemos localizado en la Sección Nobleza del Archivo Histórico Nacional, ubicado en el Hospital de Tavera de Toledo, dentro del legado de los duques de Fernán Núñez ${ }^{14}$. Se desconoce si los dos documentos fueron solicitados por el nuncio o partió la idea del mismo embajador español, en uno de esos gestos de amistad que le caracterizaban. Lo que sí está fundamentado es que pocas personas, en Lisboa y en ese tiempo, podían ofrecer a Rannuzzi tal información y de primera mano como Gutiérrez de los Ríos. Su conocimiento personal de los principales caminos en la Península Ibérica, Francia e Italia, así como sus lecturas de lo recogido por otros viajeros ${ }^{15}$, se lo permitían. Debe tenerse en cuenta el largo viaje que el aristócrata emprendió en junio de 1772 y que le llevó por el sur de Francia (Bayona, Toulouse, Carcasona...) y el norte de Italia (Génova, Pisa, Florencia...), entre otros lugares.

\section{LA GUÍA DE VIAJE}

En el manuscrito conservado se ha añadido una portada, también a mano, donde se refiere que allí se recogen Varias rutas de Lisboa a Italia. $1786^{16}$. Igualmente ha permanecido un trozo de papel (de bordes irregulares y mal cortado) donde se informa, presumiblemente por el conde, que él fue el autor de esta guía. Sin embargo, el encabezamiento del documento indica otro título semejante: Rutas desde Lisboa a Turín, con advertencias sobre ellas. Por suerte es una copia pasada a limpio del original del conde, cuya letra era muy difícil de entender. ¿Por qué se encuentra este documento en el archivo de Fernán Núñez si debía ser usado en un complicado viaje? No es posible dar una respuesta definitiva a esta

14. AHN-SN, Fernán Núñez, C. 2037, D. 9.

15. Don Carlos refirió su conocimiento de los viajes descritos por el célebre Antonio Ponz. Véase AHN-SN, Fernán Núñez, C. 2033, D. 10. GuTiÉRrez DE los Ríos, Carlos José. Viaje de Lisboa a Madrid por Andalucía de retirada de mi embajada, pasando a la de París, año de 1787, p. 19v.

16. Nada sobre este documento se indica en las siguientes obras: Foulché-DelBosC, Raymond. Bibliographie des voyages en Espagne et en Portugal. París, 1896; García-Romeral, Carlos. Bio-bibliografia de viajeros por España y Portugal: (siglo XVIII). Madrid: Ollero y Ramos, 2000. 
pregunta. Lo más probable es que se realizaran dos copias; una se guardó en el archivo del conde y la otra se usó para el viaje que, como se indica en el papel recortado ya descrito, se efectuó en el mes de septiembre de 1786.

Se inicia, como es lógico, con las etapas que debían cumplir el enviado papal y su séquito en tierras lusas. El primer tramo, en barco de pequeño porte, les llevaría desde Lisboa a la otra orilla del estuario del Tajo, esto es, a Aldea Gallega, nombre que tomaba en aquellos tiempos la actual Montijo. A continuación, en sucesivas etapas, atravesarían las localidades de Estremoz, Yelves (la Elvas de hoy día) y la frontera del río Caya hasta llegar a Badajoz. Desde Mérida tomarían la dirección de Talavera de la Reina hasta Madrid. Don Carlos José sugiere que, en Talavera, el séquito puede tomar la desviación hacia Toledo y de aquí buscar el Real Sitio de Aranjuez y Madrid. Considera que, por tres leguas pero de mejor camino, bien merece desviarse. Esta ruta, al menos en la zona portuguesa donde no había opción de otro camino mejor ${ }^{17}$, es la que solía tomar Gutiérrez de los Ríos para desplazarse entre Madrid y Lisboa. Bien es cierto que, en alguna ocasión, realizó cambios, como el de desviarse hasta Cáceres para visitar a los abuelos de su esposa, doña María de la Esclavitud Sarmiento y Sotomayor ${ }^{18}$.

Tras esta primera indicación de las ciudades y los caminos, Fernán Núñez entendió que el nuncio y sus acompañantes necesitarían descansar y entretenerse. Por ello les señalaba qué maravillas les ocultaba cada lugar y aconsejaba su visita:

En Ventas Novas hay que ver el Palacio hecho por don Juan $5 .^{\circ}$ para el viaje que hizo a la raya de España cuando el casamiento de los Príncipes de Asturias y el Brasil, año de 1727 , en que no deben dejar de verse las cocinas. Con un recado al conserje, alojará a S. Eminencia en el Palacio (con el simple cubierto) y ganará en ello, pues la posada es malísima. [...]

En Mérida, el puente, la naumaquia y otros restos de antigüedades romanas. [...]

En Aranjuez, el Palacio, sobre todo el gabinete de China hecho en la fábrica del Rey en Madrid. Los jardines del Palacio, casa de las vacas a la Milanesa, y los paseos y Jardín del Príncipe, y el puente que está más allá de Aranjuez, camino de Madrid.

En Madrid, el Puente de Toledo, por donde se entra. El Palacio del Rey y sus pinturas. El del Retiro y las suyas, y los jardines. La armería. El Gabinete de la Historia Natural, y la Academia de las tres nobles artes. La iglesia de las Salesas. Las fábricas del Hospicio. El modelo de Ibarra para un palacio. El Seminario de Nobles. El Hospital General. El Jardín Botánico, el Prado y demás paseos. La plaza de los toros. La Biblioteca del Rey. Hay varias iglesias y casas, como la de Cogolludo, Alba, Santiago,

17. La conocía bien por sus viajes entre las capitales ibéricas y en sus desplazamientos para cumplimentar a la corte lusa cuando se trasladaba al palacio de Vilaviçosa.

18. Por Talavera regresó desde Lisboa para tomar posesión del Toisón de Oro, en mayo de 1783. Véase AHN-SN, Fernán Núñez, C. 2033, D. 1. GutiérRez De los Ríos, Carlos José. Ruta general y asiento de los viajes del Conde de Fernán Núñez, d. Carlos de los Ríos. Años de 1746 a 1793, p. 26v. 
Torrecilla, y otras en que hay varias pinturas dignas de verse, sobre todo en la primera como Duque de Santisteban ${ }^{19}$.

La siguiente fase del recorrido la ubica don Carlos José entre Madrid y Barcelona. Como en el caso anterior, ofrece al nuncio dos opciones para llegar a la Ciudad Condal: por Valencia o por Zaragoza. Como la distancia en leguas es similar, y los caminos parecidos en lo malo, opta por dejar a la discreción del cardenal el tomar un camino u otro. Sin embargo, antes de partir hacia Barcelona, el conde se permite aconsejar a Rannuzzi, de manera sutil, que no sería correcto abandonar Madrid sin haber visitado a Carlos III en su palacio de San Ildefonso ${ }^{20}$. Una vez en Barcelona, la fase francesa del viaje comenzaría en Perpiñán y atravesaría las tierras de Narbona.

Sin embargo, don Carlos intenta ofrecer, siempre que es posible, alternativas a su amigo, por lo que se muestra partidario de ingresar en el país vecino por la zona de Irún. Toma, para ello, dos excusas. La primera, que una vez en San Ildefonso para cumplimentar a Su Majestad y ver el magnífico palacio y sus jardines ${ }^{21}$, lo conveniente sería ahorrar camino, no regresar a Madrid y continuar la ruta por Segovia (visitando su catedral y el acueducto, así como el Colegio de Cadetes de Artillería que fundó en 1764 don Félix Gazzola), Valladolid, Burgos (con parada en la catedral gótica y Las Huelgas), Vitoria y lograr el acceso a Francia por Bayona. La segunda excusa, que este camino ofrece mayor entretenimiento al viajero que el de Valencia y Barcelona, donde Fernán Núñez especifica un menor número de lugares a visitar que por Segovia y Bayona.

Una vez en Bayona, la siguiente gran ciudad de referencia es Tolosa [Toulouse], aunque, "Ocho postas después de Bayona está Tarbes, y de allí a las célebres aguas de Bañeras [Bagnères-de-Bigorre], hay solo una posta, que yo hice para verlas ${ }^{22}$. Como se puede comprobar, Fernán Núñez no solo utilizó sus conocimientos de los caminos y de las ciudades, sino que incluyó algunas consideraciones personales sobre su presencia en ellas. Este trayecto, tras una breve parada en Carcasona $^{23}$, finalizaría en Narbona. Ya sería cuestión del nuncio elegir entre hacer más leguas ${ }^{24}$ por Bayona que por Barcelona, a cambio de mejor camino, mejores comidas y camas, y más lugares que visitar.

19. AHN-SN, Fernán Núñez, C. 2037, D. 9, n. 2. GutiéRrez de los Ríos, Carlos José. Rutas desde Lisboa a Turin, con advertencias sobre ellas, p. 1.

20. Idem, p. $2 \mathrm{r}$.

21. De camino habría visitado «El Escorial, cuyas pinturas y edificio, librería, Panteón Real y las casas de campo del Príncipe de Asturias e infante don Gabriel, merecen verse». Ibidem.

22. Idem, p. $2 \mathrm{v}$.

23. Llama la atención que, de Carcasona, Fernán Núñez no refiera la ciudad amurallada sino la fábrica de paños como lugar de visita preferente.

24. Fernán Núñez también señala la diferente medida de la legua española y la legua francesa, de menor longitud. 
Desde Narbona don Carlos vuelve a considerar los diferentes caminos para llegar a Turín. El primero, con partida en Niza y directo a Turín, "no está practicable para coche, según me ha asegurado el Conde de Front ${ }^{25}$. Tampoco aconseja que se navegue desde Niza hasta Génova y se siga un camino hacia el norte, en pésimo estado, hacia la capital piamontesa. Esta variante por mar ya la utilizó don Carlos en su gran viaje del año 1772, pero su destino estaba en el centro de Italia, de ahí que, ahora, no aconseje utilizarlo al tener que ir en dirección contraria. Por tanto ve más factible viajar de Niza a Nimes ("Allí hay que ver el anfiteatro, los restos de un famoso templo y otras antigüedades y cosas curiosas") ${ }^{26}$, Aviñón y León [Lion]. Una vez en esta ciudad, queda enfrentarse a los Alpes: "El camino de allí a Turín son 71 postas bien conocidas con el paso del Montseny, que en fines de septiembre y a principios de octubre estaría aún muy practicable» ${ }^{27}$.

\section{CONSEJOS PARA UN VIAJE SIN SOBRESAlTOS}

Las indicaciones del conde de Fernán Núñez no se limitaron a describir los caminos, posadas, ciudades, monumentos, fábricas o leguas que debía recorrer el cardenal si quería regresar a Roma. Don Carlos comprendió que, para una aventura de este tipo, debía facilitarle más conocimientos sobre los medios de transporte. Por tanto, mientras la ruta transcurriese por tierras de Portugal y España, su consejo era el siguiente:

Es preciso tomar mulas españolas de colleras. Estas vendrán aquí a tomar a S. Eminencia y lo conducirán hasta Madrid, previniéndoles han de ir por Toledo y Aranjuez. En Madrid podrá hacer de nuevo ajuste hasta Bayona con otros carruajeros, o con los mismos proponiéndoles lo conveniente de antemano y ajustando por cada día de detención que haga en los Sitios u otra parte.

Su Eminencia deberá llevar consigo su cama y un cocinero y un mozo práctico del país, que se adelante para tenerle pronta la comida y alojamiento ${ }^{28}$.

Con estos últimos detalles daba cuenta el embajador español de otra dificultad en los traslados durante el siglo XVIII: no siempre existía habitación disponible en las posadas y, cuando sí se encontraba, tampoco era seguro que contase con una cama o el lecho se adecuase a la alcurnia del viajero. En cuanto al cocinero, la advertencia puede referirse a la necesidad de disponer de alguien que conozca

25. AHN-SN, Fernán Núñez, C. 2037, D. 9, n. ${ }^{\circ}$ 2. GutiérRez DE los Ríos, Carlos José. Rutas desde Lisboa a Turín, con advertencias sobre ellas, p. 2v. Obsérvese cómo Fernán Núñez, cuando no utiliza sus propios conocimientos, se vale de los consejos de gente de su mayor consideración, todo con el fin de ofrecer a su amigo el nuncio unas acertadas indicaciones.

\footnotetext{
26. Idem, p. $3 \mathrm{r}$.

27. Ibidem.

28. Idem, p. 3v.
} 
los gustos culinarios del cardenal -refinados, con toda seguridad- o a la escasa calidad de la comida ofertada en las posadas. En cualquier caso, nótese la permisividad en aquellos tiempos para que alguien ajeno al establecimiento trabajase en su cocina, posiblemente por tratarse del criado de un alto dignatario. En lo referente al "mozo práctico del país», don Carlos era consciente de que su guía manuscrita podría ser una ayuda eficaz en el viaje, pero no la solución a todos los problemas que surgiesen. Las circunstancias del día a día, del cambio de idioma, así como el variable carácter de los habitantes de diferentes países y regiones, hacían necesaria la contratación de alguien que conociese bien a las gentes con las que iban a tratar. Esta situación era más frecuente de lo que podría suponerse:

Como en no pocos albergues y posadas, la sala principal o el zaguán de entrada (que servían de comedor durante el día), estaban provistos de camas adosadas a las paredes, al llegar la noche se abatían, y aquellos recintos quedaban convertidos en un dormitorio general donde reposaban los viajeros de ambos sexos. Descartando las posadas modestas o los albergues rústicos [...] algo similar ocurría en otros "hoteles» de más viso, donde el número de camas solía ser inferior al de huéspedes, sobre todo si se trataba de un lugar con relevo de postas $^{29}$.

Una vez en zona francesa, don Carlos confirma al nuncio la ventaja que supone utilizar la red de transporte que ofrecen las postas galas. Por tanto, aconseja a Rannuzzi que utilice estas y no contrate con particulares. Solo le indica que tenga la precaución de enviar un correo para que avise con tiempo de su llegada a la siguiente posta, con el fin de que no le falten nunca caballos frescos y un lugar aceptable donde comer y ampararse. Por tanto, en base a su experiencia, Fernán Núñez procura en todo momento adelantarse a los posibles inconvenientes que pudieran acechar a su amigo en el viaje, evitándole disgustos y retrasos innecesarios.

\section{EL ACERTADO COMPLEMENTO: UN MAPA MANUSCRITO}

No obstante la detallada descripción de la guía anterior, Fernán Núñez ofreció otra importantísima ayuda al nuncio: le entregó un mapa de Portugal, España y sur de Francia hasta los Alpes y Turín ${ }^{30}$. Aunque su número de archivo es anterior al de la ruta, lo más probable es que se diseñase con posterioridad a aquella. Este mapa, de gran valor para la investigación de los viajes en el siglo XVIII, está dibujado a mano, pero con letra diferente a la del conde. Sobre su origen no es posible, con los datos disponibles, ofrecer una exacta conclusión. Pudo haber sido diseñado por el propio noble y más tarde copiado en limpio, o dictado por don

29. Olaechea Albistur, Rafael. Op. cit., p. 226.

30. AHN-SN, Fernán Núñez, C. 2037, D. 9, n. ${ }^{\circ}$ 1. GutiérRez de los Ríos, Carlos José. Rutas desde Lisboa a Turín, con advertencias sobre ellas, mapa. 
Carlos, o dibujado a partir de la ruta anterior. Recoge, mediante líneas de puntos, las rutas que se indican en la guía y, sobre ellas, se ubican los nombres de las ciudades, lo cual debía servir como orientación en el viaje y como aviso de los lugares que merecía la pena visitar. A la derecha del plano se encuentra una tabla con las distancias entre las principales ciudades de las diferentes rutas, lo cual es otro añadido que aporta valor al documento y lo acerca a los mapas que, hasta la irrupción de los medios informáticos, se han usado para viajar por carretera.

\section{CONCLUSIONES}

En el estudio anterior se ha comprobado cómo con la descripción de las rutas y el añadido del mapa, Gutiérrez de los Ríos ofreció dos instrumentos a un amigo que ahora pueden ayudar a entender mejor la manera en que se planeaban algunos viajes en el siglo XVIII. Aunque de los viajes en aquella época se hicieron relatos y novelas, en los que no siempre fue posible discernir lo verdadero de lo

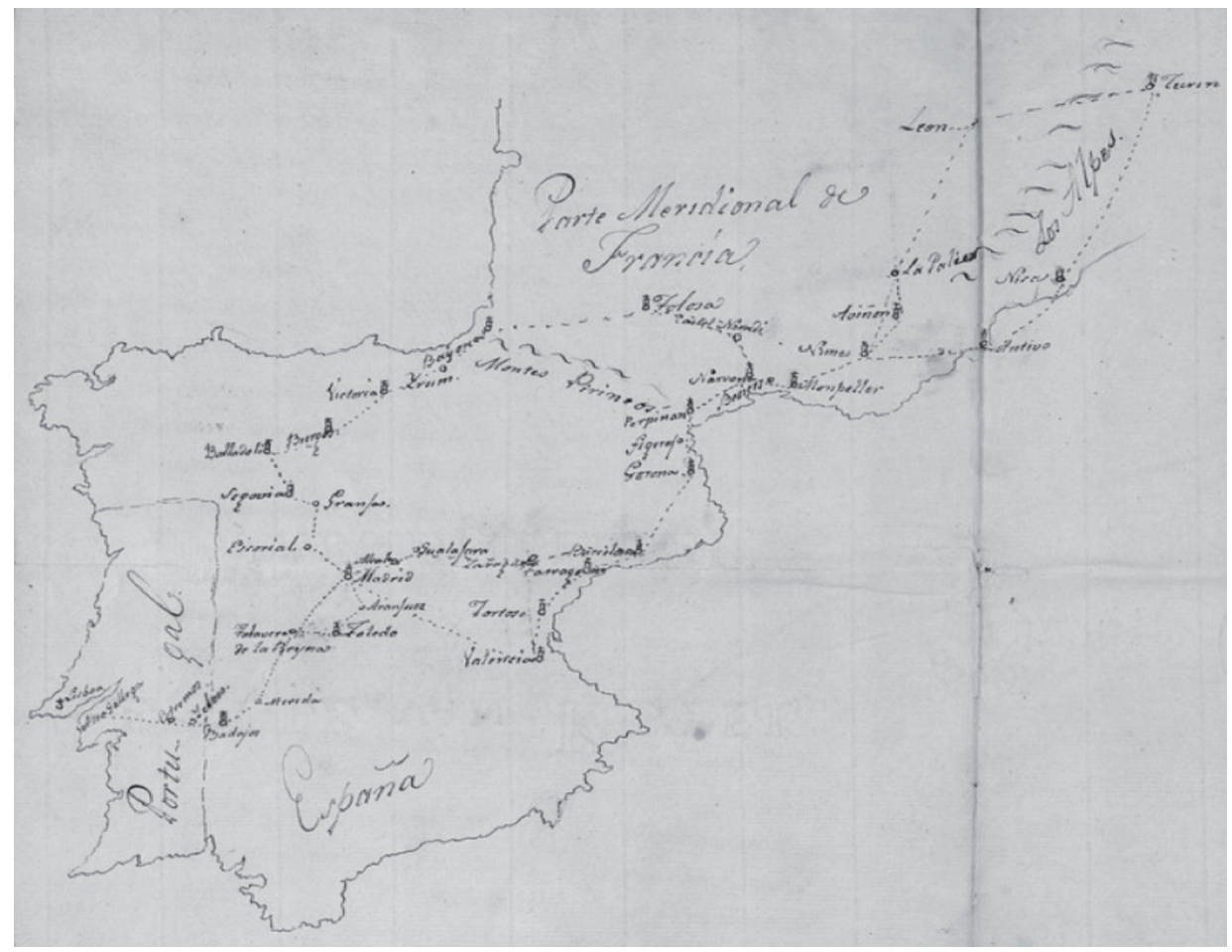

Figura 1. Mapa del documento Rutas desde Lisboa a Turín, con advertencias sobre ellas. AHN-SN, Fernán Núñez, C. 2037, D. 9, n.ำ1. 
POR LOS CAMINOS DE EUROPA EN EL SIGLO XVIII: EL VI CONDE DE FERNÁN NÚÑEZ Y SU GUÍA DE VIAJE ...

\begin{tabular}{|c|c|}
\hline EXPLICACIÓN DE LAS DISTANCIAS & LEGUAS \\
\hline De Lisboa a Talavera de la Reina & $771 / 2$ \\
\hline De Talavera a Madrid, camino recto & $19^{1 / 2}$ \\
\hline De Talavera a Madrid por Toledo y Aranjuez & 22 \\
\hline De Madrid a Valencia & 50 \\
\hline De Valencia a Barcelona & 50 \\
\hline De Madrid a Zaragoza & 50 \\
\hline De Zaragoza a Barcelona & 50 \\
\hline De Madrid a San Ildefonso, ir y venir & 28 \\
\hline De Barcelona a Perpiñán & 30 \\
\hline De Perpiñán a Narbona 7 postas, que son leguas en España & $121 / 4$ \\
\hline De Madrid a Bayona por El Escorial, San Ildefonso, Segovia [...] y Vitoria & 110 \\
\hline De Bayona a Tolosa & $573 / 4$ \\
\hline De Tolosa a Narbona 19 postas que son leguas & $16 \frac{1}{2}$ \\
\hline De Narbona a Niza 50 postas que son leguas & $871 / 2$ \\
\hline De Narbona a Nimes 15 1/2 postas & $253 / 4$ \\
\hline De Nimes a Lapalu [Lapalud] por Aviñón 13 postas & $223 / 4$ \\
\hline De Nimes a Lapalu vía recta 8 postas & 14 \\
\hline De Lapalu a León [Lyon] 23 1⁄2 postas & 41 \\
\hline $\begin{array}{l}\text { De León a Turín } 31 \text { postas (que son poco más o menos, por razón } \\
\text { de las últimas postas de Piamonte) }\end{array}$ & 54 \\
\hline
\end{tabular}

Tabla 1: Distancias en leguas calculadas por el Conde de Fernán Núñez. Elaborado a partir del original. AHN-SN, Fernán Núñez, C. 2037, D. 9, n. 1.

inventado para fomentar la posterior venta de la narración ${ }^{31}$, en el documento analizado todo lo reseñado debe considerarse cierto y escrito con el solo ánimo de ofrecer ayuda y consejo; solo algún rasgo subjetivo podría señalarse como diferente a la simple descripción verídica de los lugares a recorrer. Si al redactarlo el aristócrata español desea "que estas noticias sean útiles a Su Eminencia y le recuerden en su viaje su deseo de complacerle en todos destinos ${ }^{32}$, su intención puede resultar en nuestros días un documento fundamental para el estudio de los desplazamientos terrestres, con su riqueza de noticias sobre lugares, monumentos, costumbres y distancias.

31. Véase Pimentel, Juan. Testigos del mundo: ciencia, literatura y viajes en la Ilustración. Madrid: Marcial Pons, 2003, p. 30.

32. AHN-SN, Fernán Núñez, C. 2037, D. 9, n. ${ }^{\circ}$ 2. GutiérRez de los Ríos, Carlos José. Rutas desde Lisboa a Turin, con advertencias sobre ellas, p. 3v. 


\section{FUENTES}

AHN-SN, Fernán Núñez, C. 1832, D. 5. Memorias del Excmo. Sr. Dn. Carlos José Gutiérrez de los Ríos, VI Conde de Fernán Núñez. Las publica acompañadas de un estudio biográfico el Duque de Fernán Núñez, Conde de Cervellón. Madrid, obra inédita, 1934.

AHN-SN, Fernán Núñez, C. 2033, D. 1. GutiéRRez DE los Ríos, Carlos José. Ruta general y asiento de los viajes del Conde de Fernán Núñez, d. Carlos de los Ríos. Años de 1746 a 1793.

AHN-SN, Fernán Núñez, C. 2033, D. 10. GuTtérRez DE los Ríos, Carlos José. Viaje de Lisboa a Madrid por Andalucía de retirada de mi embajada, pasando a la de París, año de 1787.

AHN-SN, Fernán Núñez, C. 2037, D. 9. GuTiéRREz DE LOS Ríos, Carlos José. Rutas desde Lisboa a Turin, con advertencias sobre ellas.

AHN-SN, Fernán Núñez, C. 2039, D. 2, n. ${ }^{\circ}$ 25. GutiérRez De los Ríos, Carlos José. Hymne des Germains, tel qu'il se chantera par-tout.

\section{BiBLIOGRAFÍA}

Blutrach Jelín, Carolina. "Autobiografía y memoria en el Diario de viajes del VI Conde de Fernán Núñez». Espacio, Tiempo y Forma (serie IV, Historia Moderna), 2016, n. 29 , pp. 65-84.

Bolufer Peruga, Mónica. "Civilización, costumbres y política en la literatura de viajes a España en el s. XVIII». Estudis, 2003, n. ${ }^{\circ} 29$, pp. 255-300.

Comellas AguirrezÁbal, Mercedes. "Viajes y aprendizaje. Del grand tour dieciochesco al viaje románticom. En NAVARRo Domínguez, Eloy (ed.). Imagen del mundo: seis estudios sobre literatura de viajes. Universidad de Huelva, 2014, pp. 67-125.

Foulché-Delbosc, Raymond. Bibliographie des voyages en Espagne et en Portugal. París:,1896.

García-Romeral, Carlos. Bio-bibliografia de viajeros por España y Portugal: (siglo XVIII). Madrid: Ollero y Ramos, 2000.

Olaechea Albistur, Rafael. "Una viajera rusa del XVIII en los Pirineos Franceses». Anales de la Universidad de Alicante. Historia Moderna, 1982, n. ${ }^{\circ}$ 2, pp. 223-224.

Rosal Nadales, Francisco José. «El VI Conde de Fernán Núñez. Un músico en la corte de Carlos III. Revista de Feria 1999, Ayuntamiento de Fernán Núñez, 1999, pp. 87-88.

Rosal Nadales, Francisco José. «El Stabat Mater del Conde de Fernán Núñez (de la mano de don Luis Bedmar y don Leo Brower)". Revista de Feria 2000, Ayuntamiento de Fernán Núñez, 2000, pp. 95-97.

Vigara Zafra, José Antonio. Arte y cultura nobiliaria en la Casa de Fernán Núñez (17001850), tesis doctoral, UNED, $2015 \mathrm{a}$.

Vigara Zafra, José Antonio. «Las obras pías del VI Conde de Fernán Núñez: ejemplo de distinción social a través de la caritas ilustrada a finales del siglo XVIII». De Arte, 2015b, n. ${ }^{\circ} 14$, pp. $119-137$. 